\title{
International Masterclasses in Particle Physics - An excellent instrument to inspire high-school students
}

\author{
Uta Bilow ${ }^{1}$, on behalf of IPPOG (International Particle Physics Outreach Group) \\ Technische Universität Dresden \\ Institute for Nuclear and Particle Physics, TU Dresden, 01062 Dresden, Germany \\ E-mail: uta.bilowetu-dresden.de
}

\begin{abstract}
Particle Physics Masterclasses are a successful tool to engage high-school students with high energy physics. Young people become scientists for one day and perform a tailor-made physics analysis involving real LHC data under the supervision of physicists. In this way students experience methods and tools used in research and gain an appreciation for fundamental science. The International Particle Physics Outreach Group (IPPOG) has organized International Masterclasses for 13 years. Each year in spring, universities and research labs in more than 50 countries worldwide open their doors and invite high-school students to experience life at the forefront of basic research. In 2016, about 13.000 young people took part in the program.
\end{abstract}

In 2017, a new facet was added to the program. On the UN International Day of Women and Girls in Science (February 11), Masterclass activities were launched by IPPOG for the first time to support and promote the access of women and girls to science education and research activities. Universities and research labs organized 10 Masterclasses for girls. About 320 girls participated in the events organized by female scientists and analyzed LHC data. 3 video conferences with CERN were held where the girls talked to CERN women scientists and learned about the careers of these role models.

The European Physical Society Conference on High Energy Physics 5-12 July, 2017

Venice

${ }^{1}$ Speaker 


\section{Introduction}

In the framework of outreach in High Energy Physics (HEP) researchers share their results and scientific methods with the general public. Individuals and groups can improve their understanding of science and scientific research. Some outreach formats also allow the public to participate in the scientific way of gaining knowledge. Activities in the area of communication, education and outreach help to secure the next generation of researches and to attract the young to scientific careers. A proven tool in HEP outreach, which stimulates high-school students' interest in STEM (Science, Technology, Engineering, Mathematics), is International Masterclasses (IMC) [1, 2]. This is a day-long activity, where high-school students are invited to a research lab or university to be particle physicists for one day. These Masterclasses have been held since 2005 and are now in more than 50 countries worldwide. In February 2017, a special edition of IMC was organized to celebrate the United Nations International Day of Women and Girls in Science (IDWGS). These Masterclasses were for female students only and were held in 10 research labs. Mainly female scientists were involved in these events in order to provide role models inspiring the girls to pursue a career in science.

\section{International Masterclasses (IMC)}

IMC is a program which conveys HEP to high-school students aged 16 to 19. Each year in spring, Masterclasses are hosted by more than 200 research labs and universities around the world. The labs invite students to be "scientists for a day" and give them the possibility to take part in an authentic research process. IMC is organized by IPPOG [3], the International Particle Physics Outreach Group, a unique network of scientists, educators and communication specialists working across the globe in informal science education and outreach for particle physics.

A typical Masterclass is composed of an introduction to particle physics, a hands-on part and a video conference with international participation. In many countries, HEP is not part of the syllabus. Therefore a Masterclass usually starts with one or two lectures where students get insight in topics and methods of basic research at the fundaments of matter and forces. Afterwards, the students perform measurements and work with real data collected by experiments at the LHC [4]. The results of this analyses are then discussed and combined in a video conference, where up to five groups from different countries participate - this conveys the international spirit of particle physics. Video conferences are hosted at CERN, Fermilab or TRIUMF, and they are mostly moderated by young scientists. The program attracts each year more than 14,000 high-school students, thus offering them the chance to close their textbooks and experience modern science first-hand.

\subsection{History of IMC}

Masterclasses in particle physics began in the UK in 1997, and are run since then by particle physicists in various institutes all over the UK. The World Year of Physics 2005, commemorating a century since Einstein's annus mirabilis, set the scene for a vast spread of the Particle Physics Masterclasses [5]. The European program started with 58 research labs in 18 
countries, more than 3000 students participated in the first international edition [6]. The program has constantly grown since then. In 2006 American students participated for the first time. In 2017, more than 14.000 young people attended one of the Masterclasses which were organized by 216 institutes in 52 countries.

\section{UN International Day of Women and Girls in Science}

While man and women make up equal parts in our society, a gender gap in science can be said to exist. Although gender equality has come a long way, women and girls continue to be excluded from participating fully in many fields of science. In order to achieve full and equal access to and participation in science for women and girls, and further achieve gender equality and the empowerment of women and girls, the United Nations General Assembly adopted a resolution in December 2015 and established February 11 as the International Day of Women and Girls in Science (IDWGS) [7]. This date should be recognized as a global celebration on equal participation and the accomplishments of female scientists. Awareness-raising events are encouraged on this date to support and promote the access of women and girls to science education and research activities.

\section{IDWGS Masterclasses}

IPPOG followed this call by organizing a special edition of Masterclasses on the IDWGS [8]. The program was advertised to all research labs and universities participating in the usual IMC and a webpage was created. In order to follow the idea of the IDWGS, institutes were encouraged to arrange Masterclasses for girls only and to involve as many female scientists as possible as tutors and mentors.

Ten institutes from Europe and South America followed the call and invited in total 320 girls. 3 Masterclasses were held on February 11 (Sat). 7 Masterclasses were already held on February 10 (Fri), because organizing the event on a Saturday was not possible for the research labs. The program on the IDWGS followed the usual Masterclass agenda. Many institutes extended the program by adding talks, discussion sessions, or visits to adapt their Masterclass to the special occasion. Details on this are given in the section below. Three video conferences, two on Friday and one on Saturday, were arranged with CERN. Each was led by two female scientists as moderators. The participating research labs and universities were located in: Barcelona, Cagliari, Cosenza, Heidelberg, Madrid, Paris, Prague, Rio de Janeiro, and São Paulo.

\subsection{Barcelona: Institut de Física d'Altes Energies}

The Institut de Física d'Altes Energies invited 40 girls to the Masterclass on February 10. In addition to lectures, hands-on session with ATLAS data, and video conference, they arranged a visit to the local tier-1 data center PIC. On February 11 researchers organized an astroparticle Masterclass (Gamma Ray Hunters) for girls [9]. Both events were advertised with a webpage (in Catalan), and a poster promoting the event has been created, with portraits of famous female scientists [10]. Figure 1 shows a group picture along with the poster. 

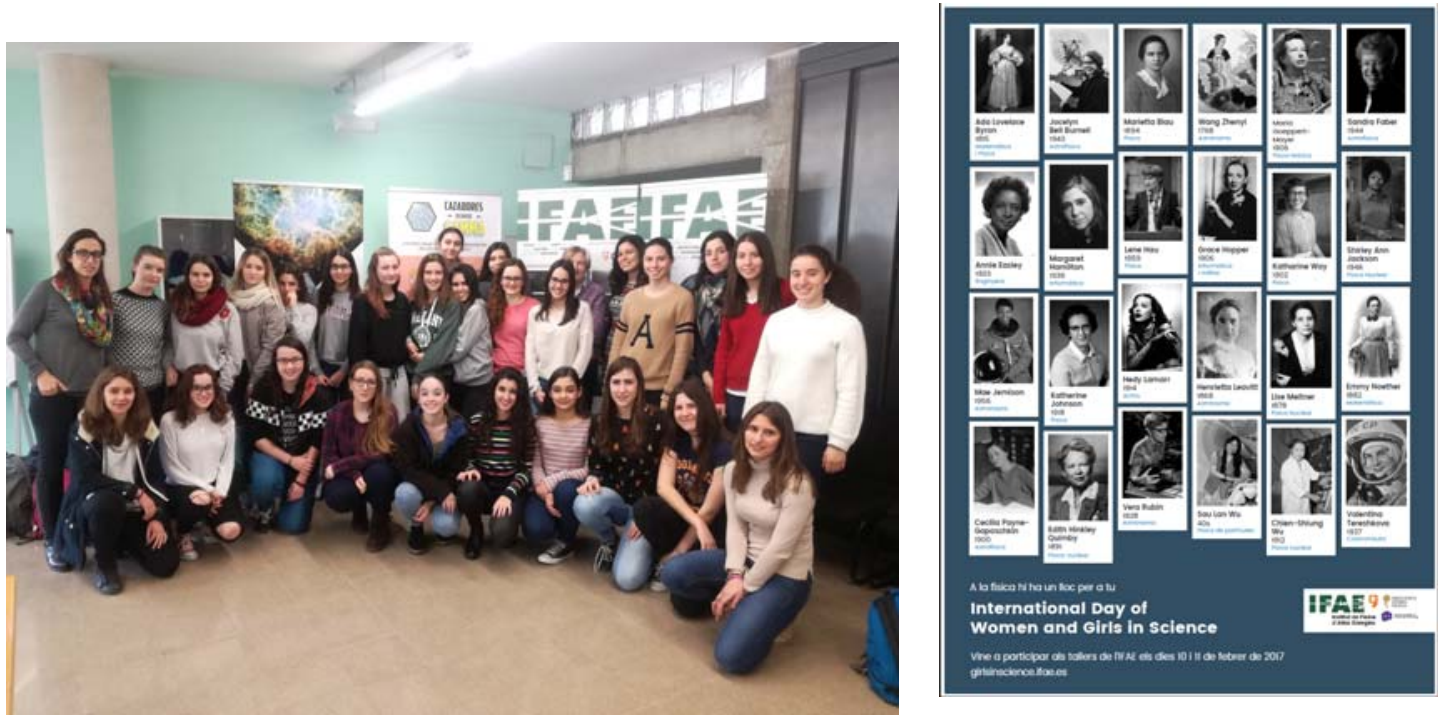

Figure 1: Group picture from the Masterclass in Barcelona, along with the advertising poster

\subsection{Cagliari: Dipartimento di Fisica dell'Universita' and Cagliari division of INFN (Istituto Nazionale di Fisica Nucleare)}

In Cagliari, researchers organized an LHCb Masterclass with 47 female participants from all over Sardinia [11]. Figure 2 shows the high-school students during the hands-on session. Issues of gender discrimination were discussed with the girls and $\mathrm{PhD}$ students and young physicists, who supervised the participants.


Figure 2: Girls in Cagliari during hands-on session (left) and lecture (right)

\subsection{Cosenza: Università della Calabria and Cosenza division of INFN (Istituto Nazionale di Fisica Nucleare)}

Organizers in Cosenza welcomed 30 girls for an ATLAS Masterclass from high-schools of the Calabria region plus a few young university students [12]. An extra talk was added to the agenda, giving information on the situation of women and girls in science in Italy and around the world. Figure 3 shows a picture of the group in Cosenza.

To foster the participation of young university students - who usually have written exams in February - in the coming years, the organizers requested the acknowledgement of February 
11 as a special day of the Physics Department dedicated to girls, in agreement with the resolution, for the next years. The Council of Physics acknowledged this request.
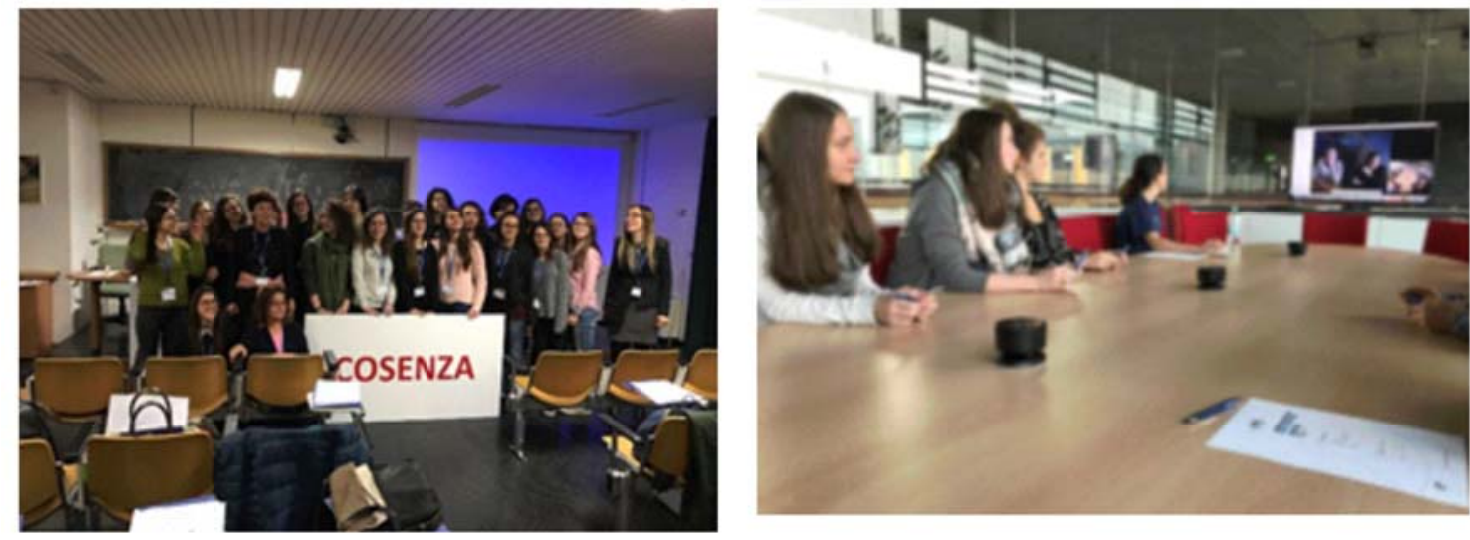

Figure 3: Participants in Cosenza (left) and a snapshot from the video conference in Heidelberg (right)

\subsection{Heidelberg: Kirchhoff-Institut für Physik, Universität Heidelberg}

In Heidelberg, the standard Masterclasses program was complemented by an informal lunch with two female scientists, where the girls (8 high-school students) could ask about university studies and careers in science. Participants analyzed data from the ATLAS experiment. A snapshot from the video conference held that day can be seen in Figure 3.

\subsection{Madrid: Centro de Investigaciones Energticas, Medioambientales y Tecnolgicas (CIEMAT)}

CIEMAT in Madrid had 40 female students attending the CMS Masterclass [13]. All lecturers and tutors were women. The program was extended by a short discussion session after the particle physics seminar, in which female scientists of the physics department talked to the students about their careers and research activities.
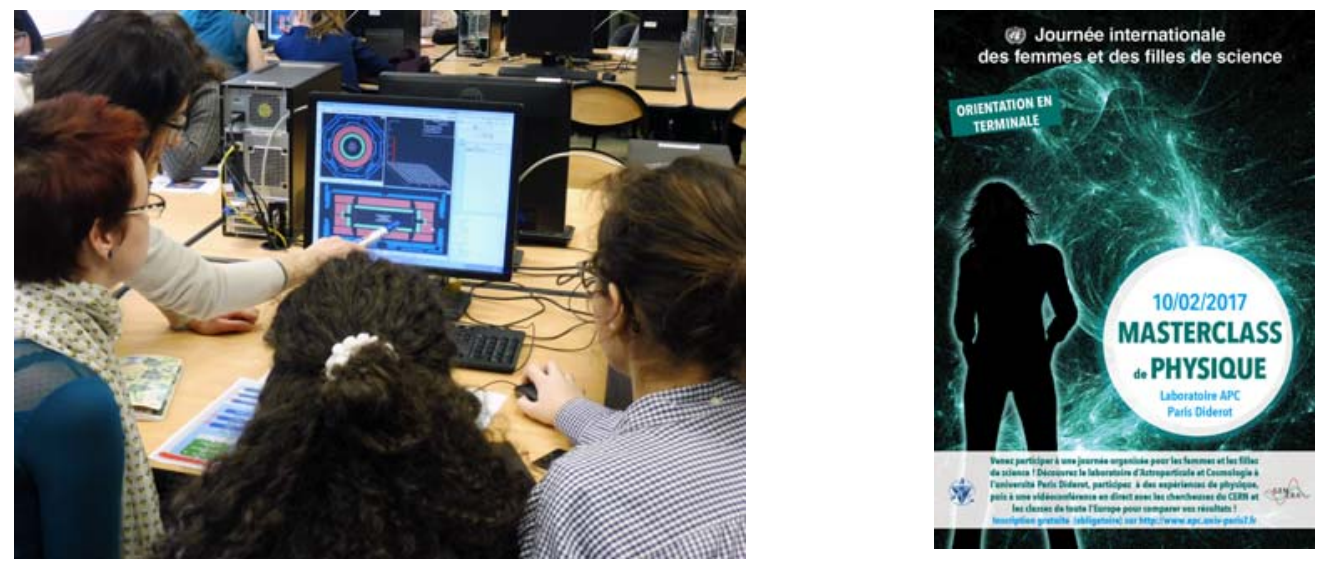

Figure 4: Girls in Paris analyzing ATLAS data, along with the advertising poster of the event 


\subsection{Paris: Laboratoire Astroparticule \& Cosmologie (APC)}

24 female high-school students attended the ATLAS Masterclass in Paris [14]. In addition to the standard agenda, two young female researchers (a $\mathrm{PhD}$ student and an engineer) introduced themselves to the girls, talked about their professional path and joined the group for lunch to discuss informally with the participants. Figure 4 shows some girls during the hands-on session, along with the advertising poster from APC.

\subsection{Prague: Czech Technical University}

The Czech Technical University in Prague arranged an ATLAS Masterclass with 14 girls from high-schools and 5 girls from first year of university [15]. Instructors and speakers were mostly women. A discussion about gender issues in science was added to the standard agenda, and a visit at the silicon detectors laboratory. The event attracted unexpected great attention from media. Besides two articles in Czech newspapers [16, 17], see Figure 5, a Czech public television sent a reporter with a team to continuously report online about the event for main news during the whole day. The summary of the event was presented in several minutes as a part of the TV news at 17:00.
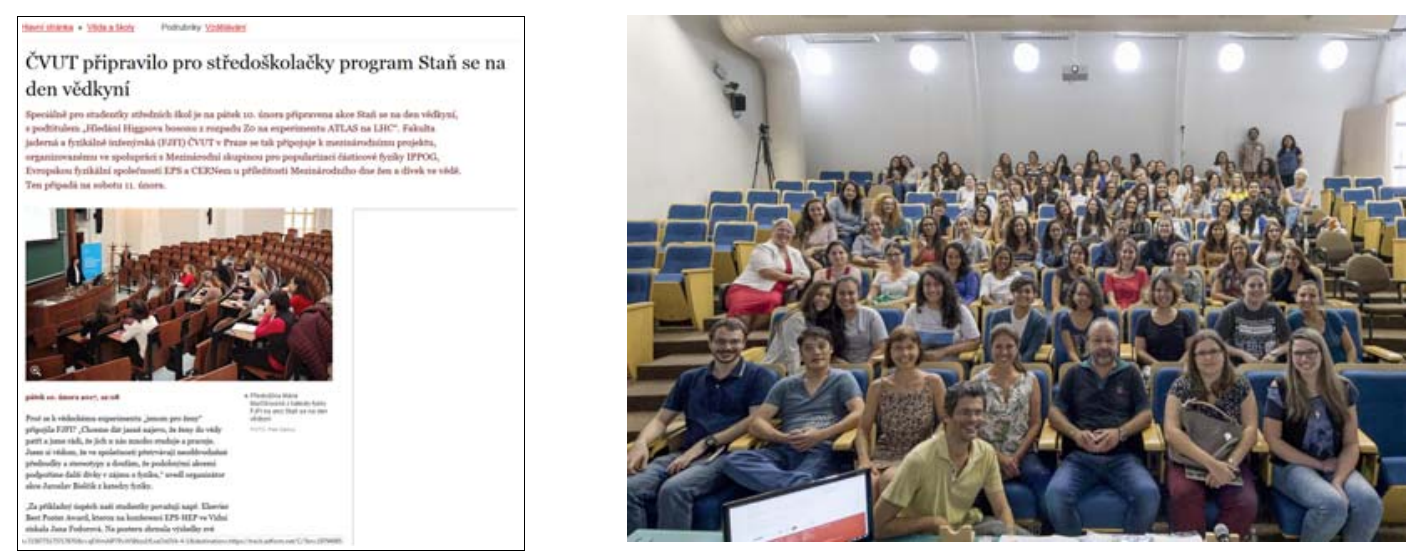

Figure 5: Clipping from a Czech newspaper reporting about the Masterclass in Prague (left) and group picture from the Masterclass in São Paulo (right)

\subsection{Rio de Janeiro: Universidade do Estado do Rio de Janeiro (UERJ)}

Due to the political and economic situation - a strike was announced for Feb 10 and 11 the State University of Rio de Janeiro had to change their plans. Originally, they had planned to hold a 2-days event with an introduction on Friday and hands-on session plus video conference on Saturday. Nevertheless they could still offer a small group of students to visit the institute, analyze data from the ATLAS experiments and participate in the video conference.

\subsection{Rio de Janeiro: Instituto de Fisica, Universidade Federal do Rio de Janeiro}

Two female scientists organized the Masterclass with 11 girls at the Universidade Federal do Rio de Janeiro, where the girls analyzed data from LHCb. A female professor, who was invited speaker, welcomed the participants. 


\subsection{Sao Paulo: São Paulo Research and Analysis Center}

The São Paulo Research and Analysis Center organized a Masterclass with CMS data for a big group; about 100 female high-school students attended the Masterclass, see Figure 5. During the day, the students also had the opportunity to talk with Brazilian researchers working in international research institutions to learn more about their career paths, difficulties and visions about gender issues in science [18].

\section{Conclusion}

Masterclasses on the International Day of Women and Girls in Science was a pilot activity in 2017. It was only announced in December, so institutes had to decide on short notice to participate. Nevertheless the pilot was a big success with ten institutes following the call, getting 320 girls to work with LHC data and stimulating their interest in science. Participating institutes were extremely satisfied as their Masterclasses for girls were very well received. The special discussions on gender issues added value also for the scientists.

IPPOG will repeat the activity in 2018. February 11 will then be a Sunday. Therefore the IDWGS Masterclasses will be held on February 12, 2018.

\section{References}

[1] http://WwW.physicsmasterclasses.org/.

[2] CERN Courier May 22, 2014, http://cerncourier.com/cws/article/cern/57305.

[3] http://ippog.org/.

[4] http://physicsmasterclasses.org/index.php?cat=physics.

[5] CERN Courier January 22, 2014, http://cerncourier.com/cws/article/cern/55890.

[6] CERN Courier September 29, 2005, http://cerncourier.com/cws/article/cern/29439.

[7] www.un.org/en/events/women-and-girls-in-science-day.

[8] http://physicsmasterclasses.org/index.php?cat=women_in_science.

[9] http://WwW.cazadoresderayosgamma.com/.

[10] http://girlsinscience.ifae.es/.

[11] http://divulgazione.dsf.unica.it/wp/women-and-girls-in-sciencealluniversita-di-cagliari/.

[12] https://agenda . infn. it/conferenceDisplay. py?confId=12775.

[13] http://11febrero.ciemat.es/girls-masterclass.

[14] https://indico.in2p3.fr/event/14122/.

[15] https://mc.casticova-fyzika.cz/program. 
[16] http://ona.idnes.cz/studium-vedy-a-techniky-divkydkf-/spolecnost . aspx?c=A170207_210457_spolecnost_haa.

[17] https://WwW.novinky.cz/veda-skoly/428995-cvut-pripravilo-prostredoskolacky-program-stan-se-na-den-vedkyni.html.

[18] https://www.sprace.org.br/divulgacao/noticias/masterclass-celebradia-internacional-das-mulheres-e-meninas-na-ciencia. 